\title{
Play Behaviors in Chinese Toddlers with Down Syndrome
}

\section{Thomas Layton ${ }^{1 *}$, Ming-Chen Chuang ${ }^{1}$ and Grace $\mathrm{Hao}^{2}$}

${ }^{1}$ Talk and Total Communication Services, 100 Meredith Drive, Suite 100, Durham, NC 27713, USA

${ }^{2}$ North Carolina Central University, 1801 Fayetteville Rd, Durham, NC 27707, USA

\begin{abstract}
Play, especially symbolic play, is one of the most significant cognitive developments in early childhood and is the precursor of representational thought and language. The current investigation compared the play behaviors of a group of Chinese children with Down syndrome matched cognitively to a group of typically developing children.

The groups were matched by cognitive development as measured by the Bayley Scales of Infant Development (Bayley). Play behaviors were determined by using the Symbolic Play Scale. The children with Down syndrome were functioning at approximately the same developmental stage as the cognitively matched typical developing children, but the children with Down syndrome exhibited behaviors that were more pre-symbolic during the earliest stages of the Symbolic Play Scale and fewer play behaviors at the highest stages. The play behaviors of children with Down syndrome correlated significantly with their chronological ages but not their developmental age. The current findings suggest that Chinese children with Down syndrome function at a similar developmental stage of play as that of younger non-handicapped peers.
\end{abstract}

Keywords: Down syndrome; Play behaviors; Chinese

\section{Background}

Play, especially symbolic play, is considered one of the most significant cognitive developments in early childhood and is the precursor of representational thought and language [1-5]. Westby [6,7] states symbolic play is a way of assessing a child's representational ability. This, in turn, is an essential prerequisite for meaningful communication [8-10]. Fein [11], for example, assessed the play in a group of typical developing children, between the ages of 12-30 months, and found that advanced receptive and expressive language skills correlated positively to mature play (e.g., pretend play) and negatively to immature play (e.g. single object play). Fein [11] concluded that children with imaginary play skills used much more sophisticated language than did children who played at less developed or more concrete levels of play. Given this conclusion, an issue of concern is whether children with less overall cognitive abilities are capable of imaginary play as well as more mature language. The purpose of the current investigation was to compare the play behaviors of a group of Chinese children with Down syndrome matched cognitively to a group of typically developing children. The children in this study were Chinese toddlers interacting with their mothers in a play situation. As far as we know, this is the initial investigation reporting on the play behaviors of Chinese children with Down syndrome.

Several investigations have focused on the play behaviors of English speaking children with Down syndrome. The overwhelming results of these investigations suggest that the play of children with Down syndrome follows a similar sequence. Play in children with Down syndrome is well organized and consistent across different domains as that of typically developing, cognitively matched children [12-20]. Motti et al. [18], for instance, examined the symbolic play of a group of children with Down syndrome and found, when adjusted for cognitive age, the children with Down syndrome play behaviors proceeded through the same sequence and at approximately the same time schedule as that of typical developing children. Motti et al. [18] also found that the individual development for both groups was consistent and coherent across domains. In another study, Hill and Nicolich [13] examined the relationship between cognition and symbolic play. They found the children' symbolic play behavior correlated highly with their cognitive age and not with their chronological age. In a third study, Wright et al. [5] explored the effects of object search and play behaviors on the social strength of children with Down syndrome. The results suggested that imitation skills were stronger features than both object search and play skills in children with Down syndrome. This supports the notion that children with Down syndrome rely mostly on social cues or imitative solutions when engaged in object search or play. An additional study, by Cunningham et al. [21] reported on the symbolic play and expressive and receptive language in a group of 73 children with Down syndrome. The investigators found no significant differences between mental ages and age equivalent scores on the children's symbolic play skills. In essence, symbolic play skills developed both as the child aged and developed cognitively.

A few studies in the literature differ slightly from the above findings. Cicchetti and Sroufe [20], for example, found that play in children with Down syndrome was consistent and well organized across affective, mental, and motor domains, and followed the same developmental sequence as in typical developing children, except play-skills were considerably delayed in the children with Down syndrome. Similarly, Smith and Tetzchner [22] found children with Down syndrome were more delayed in sensorimotor, pragmatic, and subsequent language skills. Mundy et al. [23] in another study, found children with Down syndrome displayed significant strengths in nonverbal social interaction skills, but presented with significant deficits in nonverbal requests for objects, requests for assistance, and other associated deficits in expressive language.

Research involving processing information or attending to ambiguous competing stimuli has also indicated that children with Down syndrome exhibited both quantitative and qualitative differences [15]. Landry and Chapieski [24], for instance, examined the effects of joint attention and toy exploration. They concluded that children

*Corresponding author: Thomas Layton, Talk and Total Communication Services, 100 Meredith Drive, Suite 100, Durham, NC 27713, USA, Tel: 919475-2078; Fax: 919-484-0081; E-mail: tandtcommunication@earthlink.net

Received August 13, 2014; Accepted October 28, 2014; Published November 05, 2014

Citation: Layton T, Chuang MC, Hao G (2014) Play Behaviors in Chinese Toddlers with Down Syndrome. J Psychol Abnorm Child 3: 131. doi:10.4172/23299525.1000131

Copyright: @ 2014 Layton T, et al. This is an open-access article distributed under the terms of the Creative Commons Attribution License, which permits unrestricted use, distribution, and reproduction in any medium, provided the original author and source are credited. 
with Down syndrome responded more to toys when their mothers attempted to maintain rather than to direct their attention. In a related study, Loveland [25] found that both typical developing children and children with Down syndrome, matched by mental age, demonstrated similar exploratory play behaviors, except that the children with Down syndrome differed in quantity, type, and frequency of exploration. These children used a greater number as well as a different variety of behaviors. Loveland [25] concluded that children with Down syndrome tend to use a broader, less focused selection of strategies, with more repetitive play behaviors, and they tended to continue to produce certain behaviors, while failing to inhibit less helpful strategies unless their play was redirected by the mothers.

No known investigation, to date, has reported on the play behavior of Chinese toddlers with and without Down syndrome. One related study [26] did report on the social communication skills of a group of Chinese children with Down syndrome matched to a group of typically developing children by cognitive level as well as another group of typically developing children matched by chronological age. The results of this investigation demonstrated that children with Down syndrome's communication skills were similar to the age-matched group but were better than the cognitive matched group. Therefore, experiences across developmental age by Chinese children with Down syndrome were instrumental in acquiring communication skills independent of their cognitive level.

\section{The present study}

While existing investigations shed some light on the play skills of individuals with Down syndrome, research is needed among young Chinese children with Down syndrome. The current study attempts to expand on the previous research in play behaviors and more specifically to describe the symbolic play of a group of Chinese toddlers with Down syndrome compared to a group of typical developing toddlers, matched by cognitive abilities. The following questions were addressed in the study:

1. Are there differences in the symbolic play behaviors of Chinese toddlers with Down syndrome and cognitively matched, typically developing toddlers?

2. Are the two groups functioning at the same developmental level as far as play behaviors are concerned?

3. Do children with Down syndrome display delayed development in their play behaviors compared to cognitively matched, typically developing toddlers?

\section{Methods}

\section{Participants}

The current study included sixteen Chinese toddlers from the Taipei Taiwan area. Each child was included in the study based on several criteria: sex, parent education, and scores on the Bayley Scales of Infant Development (Bayley) [27] (Table 1). There was one group of children with Down syndrome $(\mathrm{N}=8 ; 4$ boys and 4 girls $)$ and one group of typically developing children ( $\mathrm{N}=8 ; 4$ boys and 4 girls). The parent education was matched roughly by the highest educational level obtained by either the father or the mother. In both groups (i.e., the children with Down syndrome and the typically developing), six of the parents were high school graduates and two were college graduates. Although it would have been valuable to include a younger typically developing group of children for comparison, age matching with typically developing individuals results in a mismatch in relevant

\begin{tabular}{|c|c|c|c|c|c|c|c|c|}
\hline & \multicolumn{2}{|c|}{$\begin{array}{c}\text { Chronological } \\
\text { Age in Months }\end{array}$} & \multicolumn{2}{|c|}{ Bayley* } & \multicolumn{2}{c|}{ Sex } & \multicolumn{2}{c|}{$\begin{array}{c}\text { Parent's } \\
\text { Education }\end{array}$} \\
\hline $\begin{array}{c}\text { Matched } \\
\text { Pairs }\end{array}$ & DS & TD & DS & TD & DS & TD & DS & TD \\
\hline 1 & 20.6 & 12 & 108 & 109 & F & F & H.S. & H.S. \\
\hline 2 & 27.3 & 12.5 & 111 & 111 & F & F & H.S. & H.S. \\
\hline 3 & 22.5 & 12.8 & 116 & 114 & M & M & H.S. & H.S. \\
\hline 4 & 21.5 & 13.1 & 107 & 108 & M & M & H.S. & College \\
\hline 5 & 26.6 & 16.9 & 116 & 122 & F & F & H.S. & H.S. \\
\hline 6 & 25.7 & 17 & 112 & 125 & M & M & College & H.S. \\
\hline 7 & 27.5 & 18.3 & 126 & 124 & F & F & H.S. & College \\
\hline 8 & 24.8 & 19.3 & 135 & 134 & M & M & College & H.S. \\
\hline Means & 24.6 & 15.7 & 116.38 & 118.35 & & & & \\
\hline
\end{tabular}

*Bayley = Bayley's Scale of Infant Development

Table 1: Demographic information on 8 children with Down syndrome (DS) and 8 typical developing (TD) Chinese toddlers.

developmental areas such as symbolic play. This is a common limitation to research in intellectual disabilities [28].

An important matching variable was the children's performance on the Chinese version of the Bayley Scales of Infant Development (Bayley) [27]. The Bailey measures physical, motor, sensory, and cognitive development for infants and toddlers between the ages of 0-3 years. Raw scores are converted to standard scores. The cognitive domain measures the child's ability to perceive, think and gain understanding. The subjects were selected from a larger pool and consisted of only those children who matched closely by standard score quotients on the Bayley (Table 1). The mean standard score for the children with Down syndrome was 116.38 , with a range from 107 to 135 . The mean standard score for the typically developing children was 118.35 , with a range from 109-134. A t-test for matched groups was computed to determine whether the two groups were significantly different based on their Bayley scores; results yielded a non-significant difference $[t(7)$ $=-1.103, \mathrm{p}=.306]$.

The mean chronological age of the children with Down syndrome was 24.6 months, with an age range of 20.6 to 27.5 months; whereas, the mean age for the typically developing children was 15.7 months with a range of 12.0 to 19.3 months. A t-test for age confirmed that as a group the children with Down syndrome was significantly older than the typically developing children [mean difference $=9.33$ months; $[\mathrm{t}(7)=$ $10.21, \mathrm{p} 0001]]$. Therefore, the children with Down syndrome were not different in cognitive abilities but were different by roughly 9 months of age. This was as expected since children with Down syndrome typically function between 6-9 months below their cognitive level [29] and a cognitive-play relationship has been well documented previously $[1,5]$.

\section{Procedures}

A twenty-minute session was videotaped of the free-play interaction between the children and their mothers. The videotaping was conducted in a carpeted playroom ( 21 feet by $14 \frac{1}{2}$ feet). The camera was set up in the same room but in a side-sitting position so the mother would feel more comfortable. The mothers were not provided specific instructions except to play with their toddlers using any of several toys, such as, baby dolls, ring rattles, colored blocks, squeeze toys, small combs, push- and pull-car, puppets, a cooking set (pot, pan, oven, cup, plate, and spoon), balls, stacking rings, toy telephone, and a drum.

\section{Measures}

Symbolic play scale: The children's play behaviors were assessed using the Symbolic Play Scale adapted from Westby [6,7]. The scale 
consists of two checklists, one for language development and the other for play development. Only the checklist for the play development was included since the focus of the study was on children's play skills. The scale ranges from Stage I ( 9 to 12 months) to Stage $\mathrm{X}$ ( 5 years). Stages VI through $\mathrm{X}$ of the scale, or those that went beyond two and a half years of age, were not scored because the children in the study were younger than that age.

Each child's twenty-minute play session was coded according to the items listed under each stage. Some of the children were still demonstrating pre-symbolic play behaviors, such as mouthing and banging; therefore, a Stage 0 was added to the scale in order to include such behaviors (appendix). The specific play behaviors included:

Stage 0 (1-8 month old) - Play behaviors that included throwing, mouthing, banging, shaking.

Stage I (9-12 month old) - Play behaviors that included finding a toy when it was covered, locomotion to an object desired, pulling a string to obtain the toy, using a few objects appropriately.

Stage II (13-17 month old) - Stage II Play behaviors included purposeful exploration of toys (i.e., locating the part of the toy that is responsible for its operation), attempting a variety of motor schemas (i.e., pushing, pulling, turning), and handling the toy to an adult while waiting for the adult to operate the toy when he/she is not able to operate the toy him/herself.

Stage III (17-19 month old) - Stage III Play behaviors included pretend play that involved the child's own body (i.e., pretending to go to sleep, drinking from a cup, and eating with a spoon), exhibiting tooluse (i.e., attaining a toy with a stick), and using most common objects and toys appropriately.

Stage IV (19-22 month old) - Pretend play was extended to include others (i.e., feeding the doll the bottle, brushing the doll's hair, covering the doll with a blanket), acting on self as well as others (i.e., brushing his/her mother's hair as well as doll, his/her hair), and combining two toys in play (i.e., putting spoon in pan, pours from pot into cup).

Stage V (23-24 month old) - Play behaviors coded here included pretend at daily experiences (pretending to be mommy, daddy, or baby), self-limited sequencing (putting food on a plate and stirring, putting food on a plate and using a spoon to feed a doll), block play (i.e., stacking and knocking down the blocks).

\section{Scoring}

Each mother-child play interaction was transcribed onto a written text of play episodes. The play episodes were coded according to a checklist designed by the guidelines from the Symbolic Play Scale. Several principles were noted during the coding procedure. First, when a child was clearly imitating his/her mother's movement the episode was not considered a spontaneous play behavior exhibited by the child and, therefore, it was not scored. Secondly, if a child demonstrated a play episode repetitively, it was coded only once on the checklist. For example, if a child pulled a pull-telephone several times in order to get the telephone, it was coded only once on the checklist, meaning that the child was able to perform a means-end task.

After the coding was completed, a percent score was obtained by calculating how many target play behaviors were exhibited at each stage. For instance, on the checklist, there were four target behaviors at both Stage O and Stage I; and there were three behaviors at Stages II, III, IV and V. If a child was capable of exhibiting one out of the four behaviors in Stage O, he/she obtained a $25 \%$ score for that stage. In addition, an overall stage level was assigned to each child based on the criteria of the highest stage where the child exhibited $50 \%$ of the play behaviors.

\section{Reliability}

The current study established reliability by repeating the coding procedure. One of the investigators (MC) independently coded the play episodes a second time after an interval of two weeks following the original coding sessions. The two coding scores were then compared. Out of 135 play episodes, for both groups, 122 episodes were coded exactly the same with only 13 differing. A Pearson correlation produced a .90 reliability score. This high rate of reliability indicates a strong level of consistency on the scoring of the Symbolic Play Scale.

\section{Data analysis}

All group data were analyzed using SPSS file [30]. Individual item scorings were analyzed according to the percent behaviors exhibited by each child at each stage along with their group means.

\section{Results}

Several important observations were found between the two groups. First, both groups demonstrated the highest percentage of play behaviors during Stages I and II. This, according to Westby [6], would occur at a developmental age range of 9-12 months, and 13-17 months respectively. Since the age range of the typically developing children was from 12.0 to 19.3 months, it would appear that the results are consistent with Westby's data. For the children with Down syndrome, the results suggest that they too were at the same developmental stages although their chronological ages of 20-27 months suggest that they were 7-10 months delayed.

Other worthy considerations, as noted in (Table 2), are that the children with Down syndrome exhibited more play behaviors at Stage $\mathrm{O}$, or more pre-symbolic behaviors, than did the typically developing children. Furthermore, the children with Down syndrome presented less Stage IV and Stage V behaviors than did the typically developing children; that is, four of the eight children with Down syndrome did not exhibit any play behavior skills at Stage IV and five of the children with

\begin{tabular}{|c|c|c|c|c|c|c|c|}
\hline & & \multicolumn{6}{|c|}{ Play Behavior Stages* } \\
\hline $\begin{array}{c}\text { Matched } \\
\text { Pairs }\end{array}$ & Child & Stage O & Stage I & Stage II & Stage III & Stage IV & Stage V \\
\hline 1 & DS-1 & 25 & 75 & 33 & 0 & 0 & 0 \\
\hline & TD-1 & 0 & 50 & 0 & 33 & 33 & 0 \\
\hline 2 & DS-2 & 50 & 75 & 33 & 100 & 67 & 67 \\
\hline & TD-2 & 0 & 75 & 67 & 0 & 33 & 33 \\
\hline 3 & DS-3 & 25 & 50 & 100 & 33 & 67 & 33 \\
\hline & TD-3 & 75 & 50 & 0 & 33 & 33 & 33 \\
\hline 4 & DS-4 & 75 & 75 & 33 & 0 & 0 & 0 \\
\hline & TD-4 & 50 & 50 & 67 & 33 & 33 & 33 \\
\hline 5 & DS-5 & 75 & 50 & 33 & 33 & 0 & 0 \\
\hline & TD-5 & 0 & 75 & 33 & 33 & 67 & 67 \\
\hline 6 & DS-6 & 25 & 75 & 67 & 33 & 100 & 0 \\
\hline & TD-6 & 25 & 75 & 100 & 33 & 100 & 0 \\
\hline 7 & DS-7 & 0 & 75 & 67 & 67 & 67 & 0 \\
\hline & TD-7 & 75 & 75 & 100 & 67 & 33 & 33 \\
\hline 8 & DS-8 & 0 & 75 & 33 & 100 & 0 & 33 \\
\hline & TD-8 & 0 & 100 & 0 & 33 & 33 & 100 \\
\hline Means & DS & 34.4 & 68.8 & 49.9 & 45.8 & 37.6 & 16.6 \\
\hline & TD & 28.1 & 68.8 & 45.9 & 33.1 & 45.6 & 37.4 \\
\hline
\end{tabular}

*Based on Westby's (198) Play Behavior Scale

Table 2: Percentage of play behaviors exhibited by each child for each of six stages 


\begin{tabular}{|c|c|c|c|c|c|c|c|}
\hline & \multicolumn{3}{|c|}{ Down syndrome } & & \multicolumn{3}{c|}{ Typical Developing } \\
\hline ID & $\begin{array}{c}\text { Age/ } \\
\text { Months }\end{array}$ & Bayley* & Stage & ID & $\begin{array}{c}\text { Age/ } \\
\text { Months }\end{array}$ & Bayley* & Stage \\
\hline DS-1 & 20.6 & 108 & I & TD-1 & 12 & 109 & I \\
\hline DS-2 & 27.3 & 111 & V & TD-2 & 12.5 & 111 & II \\
\hline DS-3 & 22.5 & 116 & IV & TD-3 & 12.8 & 114 & I \\
\hline DS-4 & 21.5 & 107 & I & TD-4 & 13.1 & 108 & II \\
\hline DS-5 & 26.6 & 116 & I & TD-5 & 16.9 & 122 & V \\
\hline DS-6 & 25.7 & 112 & IV & TD-6 & 17 & 125 & IV \\
\hline DS-7 & 27.5 & 126 & IV & TD-7 & 18.3 & 124 & III \\
\hline DS-8 & 24.8 & 135 & III & TD-8 & 19.3 & 134 & V \\
\hline
\end{tabular}

*Bayley = Bayley's Scale of Infant Development

Table 3: The highest stage of play behaviors where $50 \%$ of the items were passed.

Down syndrome did not exhibit any play behaviors skills at Stage V. In contrast, all of the typically developing children exhibited some play behaviors skills at Stage IV and all but two did so at Stage V.

These findings indicate that the children with Down syndrome were more likely to demonstrate more early play behaviors than did the typically developing children. In contrast, the typically developing children tended to produce play behaviors that scanned all five stages of the Play Behavior Scale.

The highest stage of play behavior is located in (Table 3). As can be seen in the table, the $50 \%$ level was selected because it indicated half of the children completed that stage. Spearman rank-order correlation coefficients, comparing each of the children's highest-stage of play with their chronological age and cognitive abilities scores, indicated that the group of typically developing children's highest-stage play behaviors significantly correlated with their chronological age $(\mathrm{r}=$ $0.82, \mathrm{p}<0.02)$ as well as the Bayley scores $(\mathrm{r}=0.74, \mathrm{p}<0.05)$. In contrast, the children with Down syndrome's highest-stage play behaviors were only moderately correlated with chronological age $(r=0.62, p<0.10)$ and weakly correlated to their Bayley scores $(\mathrm{r}=0.29, \mathrm{p}<0.50)$. These findings suggest the typically developing children's age and cognitive abilities are associated closely to their play behaviors. However, for the children with Down syndrome, play behavior skills were not associated with either chronological age or cognitive abilities, as assessed by the Bayley scales. In essence, play behavior skills for children with Down syndrome appear to be independent of age and cognitive abilities.

Individual differences in behavior is worthy of further consideration. For instance, the typically developing children's play behaviors appeared to be more predictable and followed the developmental stages more consistently than did the play of the children with Down syndrome. For example, the first four youngest typically developing children (TP-1, TP-2, TP-3, TP-4), with the lower scores on the Bayley, were as expected functioning at Stages I and II on the play behavior scale. In contrast, only one of the three youngest children with Down syndrome (DS-3) was functioning at Stage IV while the other two children (DS-1, DS-4) were at Stage I. This is a decidedly different stage performance considering both groups of children were all at similar cognitive levels on the Bayley. Furthermore, one child with Down syndrome (DS-3), with a lower Bayley score, was performing at the highest play behavior Stage IV, showing a decidedly greater discrepancy of play behavior versus cognitive level.

\section{Discussion}

The primary purpose of the current investigation was to compare Chinese toddlers with and without Down syndrome on their level and type of play behaviors. Although there were few children included in the study, it is the initial investigation on the play behaviors among Chinese children with Down syndrome. Additional studies are needed to confirm the findings. However, with that in mind, it is important to note that the results indicated the Chinese children with Down syndrome were functioning at about the same stage of play behaviors as their cognitively matched typically developing peers. However, individual performances by these children indicated more of a delay in play behaviors, as evidenced by behaviors that are more pre-symbolic and fewer advanced stage behaviors, than in the typically developed children. In addition, both the children with Down syndrome and the typically developing children demonstrated consistent play behaviors at Westby's Stage I and II levels, or a level expected of most 9-12 month to 13-17 month olds. In other words, when matched by cognitive abilities, the children with Down syndrome were functioning at approximately the same stage of play as their cognitively matched typically developing peers.

Furthermore, it was found that the Chinese children with Down syndrome exhibited more pre-symbolic play behaviors than symbolic play behaviors at advanced stages (i.e., stages IV and V). These results strongly support the work of Cicchetti and Sroufe [20] and Mottie et al. [18] who also found play behaviors in English speaking children with Down syndrome followed similar sequences to that of typical developing children but at a more delayed rate. These findings also confirm the work reported by Krakow and Kopp [15] and Loveland [25] who found that children with Down syndrome had grossly similar developmental levels but qualitative and quantitative differences in play from those of typical developing children.

Wright et al. [5] found that children with Down syndrome relied more heavily on social cues from parents or imitative solutions when engaged in object play than typical developing peers. Landy and Chapieski [24] also found that children with Down syndrome responded better when mothers maintained the play behavior of their children rather than redirecting them. The current study did not investigate the mother's role in the play schemas and, in fact, discarded imitated play schemas from the coding. Perhaps coding these behaviors would have clarified more the play behavior of the children with Down syndrome. Since our mothers were actively directing their children's play, there may well have been specific behaviors elicited by the mothers that the mothers wanted in order for their children to appear more typical. If the children with Down syndrome had been left to their own devices, their play behaviors could well have been less sophisticated, as occurred in the Landy and Chapieski [24] and Wright et al. [5] studies.

There were some children with Down syndrome, especially the older ones, who actually acquired several advanced play behaviors. This suggests that as children with Down syndrome grow older, they may become more sophisticated in play; however, this occurs only as they get older and not necessarily, as they improve in cognitive abilities, since the play behaviors of the Chinese toddlers with Down syndrome did not correlate significantly with their Bayley scores.

The foregoing finding clearly differs from those of several previous investigations. Mans et al. [17], for example, found the symbolic play of children with Down syndrome correlated higher with developmental age than with chronological age. The reason why these differences occurred can be explained partially by the fact that the typically developing children's play behaviors were more predictable and followed the developmental stages more consistently than they did for the children with Down syndrome. That is, the first four youngest typically developing children had the lowest Bayley scores and functioned the two earliest stages on the play behavior scale. In contrast, the youngest 
children with Down syndrome, with similar Bayley scores, were either at the lowest or highest stages on the play behavior scale.

A factor that might have contributed to these differences could be related to the fact that the older children with Down syndrome had more daily living experiences than did their developmentally matched but chronologically younger peers. This could account for why the older children with Down syndrome exhibited more pretend play that centered on daily experiences. For example, one child with Down syndrome, who was matched to a typically developing child, had the same Bayley scores; however, the child with Down syndrome was able to pretend at daily experiences more often than the typically developing child. That is, when the child with Down syndrome did not hear anything from the toy telephone, she would test the toy telephone by patting the receiver with her hand as if it was the telephone in her grandmother's house, which was frequently broken. This is how her grandmother would test her telephone when it was broken. No such behaviors were observed in the matched typically developing children. Such differences in play behavior, therefore, could have contributed to the within group play variation found among the children with Down syndrome.

Although the examiners tried to eliminate the influence of mother's verbal and nonverbal cues on the children's play by not coding any play behavior that was a direct imitation of the mother's behavior, it was still possible that the older children with Down syndrome could have picked up their mother's cues more readily than did the younger typically developing children. Furthermore, because the children were matched only on the Bayley, other factors such as verbal and nonverbal communication, motor, and social development could have had an influence too.

It should be pointed out that the Bayley was not normed for Chinese children, although it has been adapted for this population [27]. Therefore, certain cultural factors could have influenced the results. Although, in this study, the typically developing children's scores on the Bayley did correlate significantly with their play behaviors.

These findings suggest the use of Westby's Play Behavior Scale would be a useful guide for assessing a child with Down syndrome's play behavior. In other words, if a child is at Stage II on the Scale, the teacher or therapist could introduce play behaviors at the next stage of development to assist the child to begin to increase his/her play skills. This is especially true since the current findings found that the children with Down syndrome had delayed behaviors with some play skills at higher levels. Therefore, introducing higher play behaviors could encourage and enhance increased cognitive skills and as suggested by Fein [11] intervention of play behaviors may well improve the child's receptive and expressive language skills too.

\section{References}

1. Karmiloff-Smith A (2002) Beyond modularity: A developmental perspective on cognitive science. MIT Press, London.

2. Piaget J (1976) The child's construction of reality. Routledge, London

3. Ungerer J, Zelazo P, Kearsley R, O'Leary K (1981) Developmental changes in the representation of objects in symbolic play from 18 to 34 months of age. Child Dev 52:186-195.

4. Wolfberg PJ (2003) Peer play and the autism spectrum: The art of guiding children's socialization and imagination. Shawnee Mission, KS: Autism Asperger Publishing.

5. Wright I, Lewis V, Collis G (2006) Imitation and representational development in young children with Down syndrome. Brit J Dev Psychol 24: 429-450.

6. Westby $C(1980)$ Assessment of cognitive and language abilities through play. Language, Speech and Hearing Services in School, 11:154-168.
7. Westby C (2000) A scale for assessing development of children's play. In: GitlinWeiner K, Sandguard A, Schaefer C (Eds.), Play diagnosis and assessment. Wiley, New York.

8. Garvey C (1977) Play. JA: Harvard University Press, Cambridge.

9. Meltzoff A, Moore M (1989) Imitation in newborn infants: Exploring the range of gestures imitated and the underlying mechanisms. Dev Psychol 25: 954-962.

10. Sinclair H (1970) The transition from sensory-motor behavior to symbolic activity. Interchange 1:119-126.

11. Fein GG (1981) Pretend play in childhood: An integrative review. Child Dev 52 1095-1118.

12. Cichetti D, Beeghly M (1990) The self in transition. The University of Chicago Press.

13. Hill P, McCune-Nicolich $L$ (1981) Pretend play and patterns of cognition in Down's syndrome children. Child Dev 52:611-617.

14. Kopp C, Krakow J, Johnson K (1983) Strategy production by young Down syndrome children. Am J Ment Defic 88: 164-169.

15. Krakow J, Kopp C (1983) The effects of developmental delay on sustained attention in young children. Child Dev 54: 1143-1155.

16. Mahoney G, O'Sullivan P, Robinson C (1992) The family environments of children with disabilities: Diverse but not so different. Top Early Child Spec 12 386-402.

17. Mans L, Cicchetti D, Sroufe L (1978) Mirror reactions of Down's syndrome infants and toddlers: Cognitive underpinnings of self-recognition. Child Dev 49: 1247-1250.

18. Motti F, Cicchetti D, Sroufe L (1983) From infant affect expression to symbolic play: The coherence of development in Down syndrome children. Child Dev 54: $1168-1250$

19. Sigman M, Ungerer J (1984) Cognitive and language skills in autistic, mentally retarded, and normal children. Dev Psychol 20: 293-302.

20. Cicchetti D, Sroufe $L$ (1976) The relationship between affective and cognitive development in Down's syndrome infants. Child Dev 47: 920-929.

21. Cunningham $C$, Glenn $S$, Wilkinson $P$, Sloper $P$ (1985) Mental ability, symbolic play and receptive and expressive language of young children with Down's syndrome. J Child Psychol Psychiatry 26: 255-265.

22. Smith L, von Tetzchner S (1986) Communicative sensorimotor and language skills of young children with Down syndrome. Am J Ment Defic 91: 57-66.

23. Mundy P, Sigman M, Kasari C, Yirmiya N (1988) Nonverbal communication skills in Down syndrome children. Child Dev 59: 235-249.

24. Landry S, Chapieski M (1989) Joint attention and infant toy exploration: Effects of Down syndrome and prematurity. Child Dev 60: 108-118.

25. Loveland KA (1987) Behavior of young children with Down syndrome before the mirror: exploration. Child Dev 58: 768-778.

26. Wang Y, Mao S, Xie C, Qin Y, Zhu Z, et al. (2007) Study on the social adaptation of Chinese children with Down syndrome. Yonsei Med J 48: 412-420.

27. Su C, Lu C, Wang C, Chan S, Lu S (1984) Revised Chinese version of Bayley scales of infant development. Taipei Taiwan: National Taiwan Normal University.

28. Hodapp RM, Dykens EM (2001) Strengthening behavioral research on genetic mental retardation syndromes. Am J Ment Retard 106: 4-15.

29. Layton T (2000) Young children with Down syndrome. In: Layton T, Crais E, Watson $L$ (Eds.), Handbook of early language impairment in children: nature. Delmar Thomson Learning Albany, NY.

30. SPSS (2005) SPSS for Windows, rel 10. SPSS Inc., Chicago, IL. 